
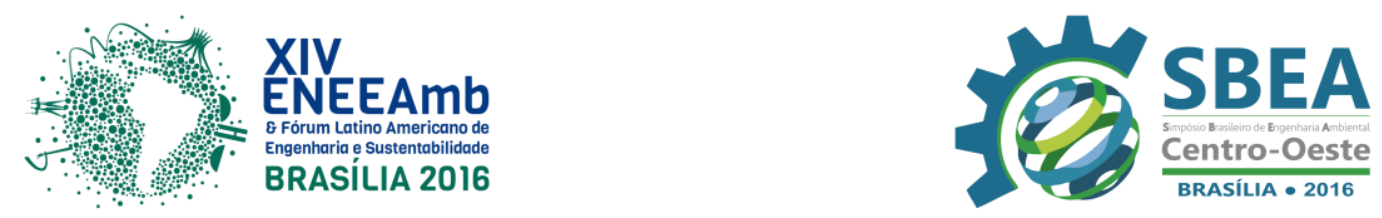

\title{
MONITORAMENTO AMBIENTAL \\ FOCOS DE CALOR EM TERRAS INDÍGENAS DO ESTADO DE RONDÔNIA
}

Lucas Joahay de Lucena Ferreira - lucasjoahay.engenharia@ gmail.com

Universidade Federal de Rondônia.

Cláudia Corrêa dos Santos - claudiacorrea.engenharia@mail.com

Universidade Federal de Rondônia.

Bárbara Antonucci - antonucci.engenharia@gmail.com

Universidade Federal de Rondônia.

Naara Ferreira Carvalho de Souza - naaraferreira94@gmail.com

Universidade Federal de Rondônia.

Alex Mota dos Santos - alex.geotecnologias@gmail.com

Universidade Federal de Goiás.

Resumo: A ocupação amazônica, através do avanço das práticas de desmatamento, com destaque para o Estado de Rondônia, ocasionou a supressão da vegetação, a perda da biodiversidade, além de pressões sobre as Terras Indígenas (TI). Diante disto, o presente trabalho analisou os focos de calor, bem como sua densidade em todas as TI em Rondônia. A realização das análises partiu da utilização de dados sobre focos de calor disponibilizados pelo INPE para os períodos úmido, úmido-seco, seco e seco-úmido de 2015 e, o processamento dos mesmos foi determinado pelo estimador de densidade Kernel do programa ArcMAP®, versão 10.1. Para o período seco, as TI com maiores focos de calor foram Karipuna, Rio Branco e Sete de Setembro, com 226, 148 e 115, respectivamente, enquanto que, para o período seco-úmido, a maior incidência de focos foi registrada na extremidade oeste do estado, destacando as TI Sagarana, Rio Guaporé e Pacaás Novos, evidenciando assim, o efeito de borda. Desta forma, os altos índices de focos de calor ocorridos nos limites de TI podem estar relacionados à deficiência na fiscalização do estado.

Palavras-chave: Monitoramento ambiental, Kernel, Geoprocessamento, Pressões antropogênicas, Efeito de borda 

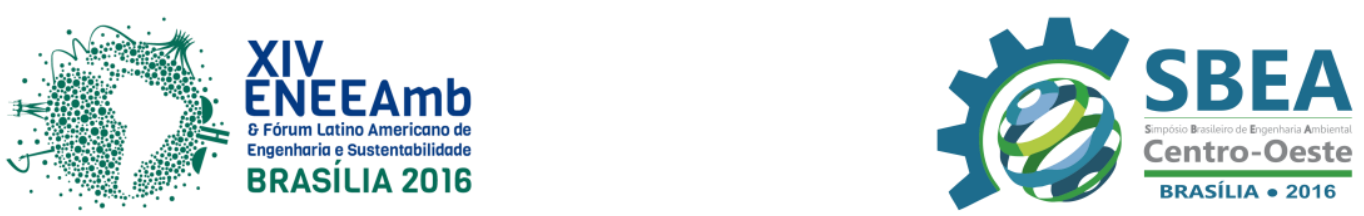

\section{INTRODUÇÃO E OBJETIVOS}

A população indígena brasileira decresceu de forma acentuada de 1500 até meados de 1970, levando à extinção de muitos povos (FUNAI, 2013). Nas últimas décadas, mesmo com a atuação de órgãos indigenistas, cujo intuito é promover a proteção e o bemestar das comunidades, grande parte destes povos ainda enfrentam um acelerado e complexo processo de transformação sociocultural e espacial, muitas vezes, vinculados às disputas por territórios.

O avanço contínuo do desmatamento sobre os estados da Amazônia leva à perda da cobertura florestal, modificando ecossistemas nativos, extremamente ricos em espécies vegetais e animais (VITEL et al. 2009). Segundo dados do IPEA (2010), as práticas de retirada da vegetação, sendo caracterizadas pelo corte, capina ou queimada, incidem negativamente sobre a biodiversidade, acarretando pressões sobre as Terras Indígenas (TI).

Neste contexto, o Instituto Nacional de Pesquisas Espaciais (INPE) realiza o monitoramento operacional de focos de calor e de incêndios florestais, detectados por satélites, além do cálculo e previsão de possíveis riscos. De acordo com o INPE (2016), tal monitoramento é importante, uma vez que os dados gerados permitem uma melhor percepção dos impactos causados à biodiversidade, o que afeta diretamente as comunidades indígenas.

Dessa forma, o presente estudo objetiva analisar os focos de calor bem como sua densidade em TI no estado de Rondônia.

\section{METODOLOGIA}

\section{1. Área de estudo}

A pesquisa foi realizada em todas as TI do estado de Rondônia (Figura 1), as quais, segundo Santos e Gomide (2015), compreendem 21,31\% do território do estado. A população indígena de Rondônia, estimada no último censo foi de 13.076 pessoas, sendo que destas, 9.388 são residentes de TI (IBGE, 2010).

Sobre a caracterização dos aspectos físicos do Estado o clima predominante, de acordo com a classificação de Köppen, é o Aw - Tropical Chuvoso, com média climatológica da temperatura do ar durante o mês mais frio superior a $18{ }^{\circ} \mathrm{C}$, e um período seco bem definido durante a estação de inverno, onde ocorre um ameno déficit hídrico com índices pluviométricos inferiores a $50 \mathrm{~mm} / \mathrm{mês}$ (SEDAM, 2010).

Assim, para a determinação dos focos de calor no decorrer do ano de 2015, os dados foram separados por período úmido, de janeiro a março, úmido-seco, de abril a junho, seco, julho a setembro e por fim seco-úmido (WEBLER et al., 2013), visando caracterizar a sazonalidade do clima da região descrita anteriormente. 


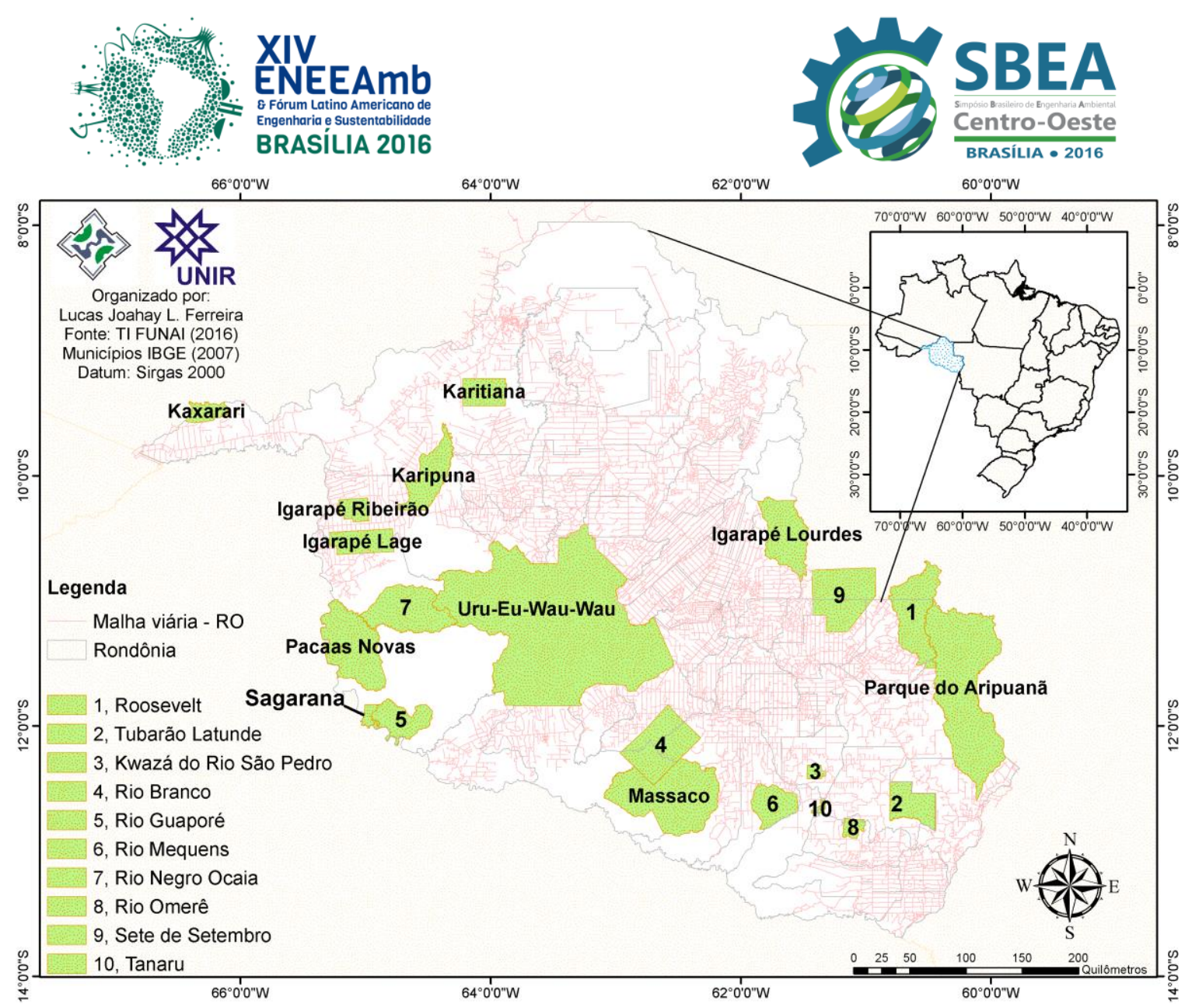

Figura 1 - Terras Indígenas localizadas no estado de Rondônia.

\subsection{Utilização de Software}

Os arquivos vetoriais em formato shapefile utilizados neste estudo, que incluem os limites dos municípios, as TI e os focos de calor, foram obtidos na base cartográfica do IBGE, FUNAI e do INPE, respectivamente.

Segundo Gontijo et al. (2011), os focos de calor são definidos como qualquer temperatura registrada acima de $47^{\circ} \mathrm{C}$, não sendo necessariamente um foco de incêndio.

Os dados foram processados e espacializados através do programa ArcMAP®, versão 10.1, gratuita para estudante, a partir do uso do estimador de densidade Kernel, disponível na ferramenta Spatial Analyst.

O estimador de densidade Kernel desenha uma vizinhança circular ao redor de cada ponto da amostra, correspondendo ao raio de influência, e então aplica uma função matemática de 1 a 0 na posição do ponto, na fronteira da vizinhança (SOUZA et al., 2013). Após aquisição e manipulação dos dados foram elaborados mapas temáticos representando os focos de calor e a densidade Kernel, classificada em 5 níveis, variando de acordo com a cor e tonalidade, sendo a tonalidade vermelha a mais "crítica".

\section{RESULTADOS E DISCUSSÕES}

Os resultados principais revelaram que no ano de 2015 observou-se que as maiores incidências de focos de calor ocorreram no período seco e seco-úmido, evidenciados na Figura 2. 

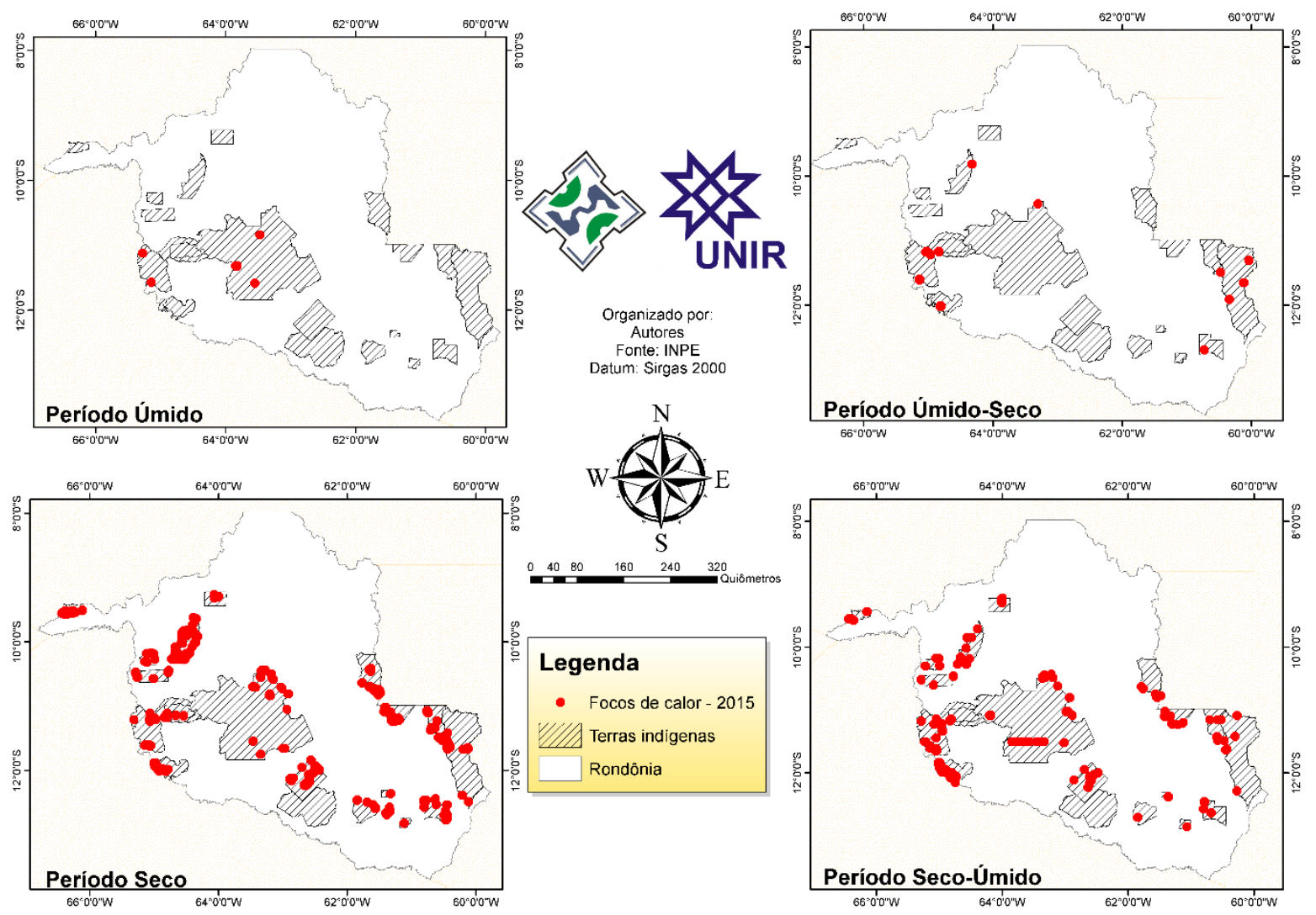

Figura 2 - Focos de calor nas TI de Rondônia nos períodos Úmido, Úmido-Seco, Seco e SecoÚmido no ano de 2015.

Ao analisar os focos de calor verificados no período úmido em comparação com os períodos úmido-seco e seco, constatou-se um aumento de $82 \%$ e 99,5\% na incidência dos mesmos nas áreas de entorno das TI, respectivamente. Corroborando com os dados apresentados, Aragão et al (2009) afirma que este comportamento é comum na região sul e leste da Amazônia, onde as queimadas ocorrem geralmente entre julho e setembro, período caracterizado pela estiagem, época em que se intensificam as atividades de limpeza da pastagem para renovação do plantio. Reforça-se que tais práticas são ilegais, quando não excetuadas pelo Art.38 da lei 12.651, de 25 de maio de 2012.

Sendo assim, em um estudo realizado por Abreu et al. (2015) no leste do Mato Grosso, entre os anos de 2005 e 2010, a maior concentração de focos de calor também foram encontrados no período seco, onde segundo o autor, não ocorrem raios nessa região, com isso, é levantada a hipótese de que esses focos sejam provenientes de ações antrópicas. De forma semelhante, a maior concentração de focos de calor para o estado de Rondônia ocorreu no período seco, entretanto, a incidência desses focos se prolongou pelo período seco-úmido, onde comumente iniciam-se as maiores taxas de pluviosidade no mês de outubro, sendo isto atribuído ao fenômeno do El Niño, que acarretou um prolongamento da estiagem durante o ano de 2015.

As maiores concentrações de focos de calor ocorreram nas bordas das TI, evidenciando o efeito de borda. Desta maneira, em um estudo que visava quantificar os 

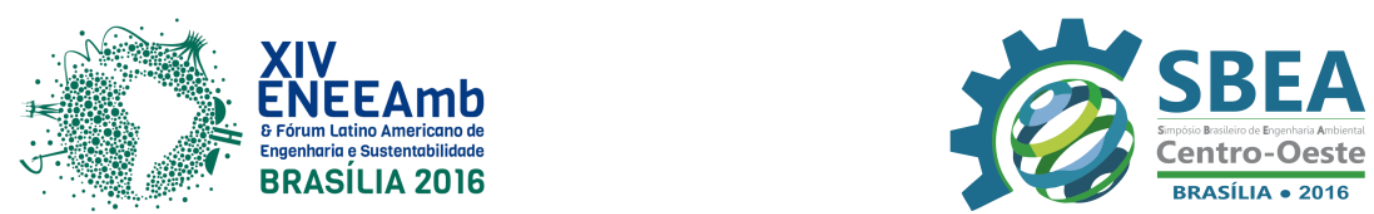

efeitos de borda nas TI do estado, Santos e Gomide (2015), constataram que em seu entorno, a pecuária e a agricultura, ocupam $21,41 \%$ e $4,26 \%$ do uso da área, respectivamente, enquanto os outros $65 \%$ correspondem a floresta nativa.

Durante o período seco, as TI com maiores focos de calor foram Karipuna, Rio Branco e Sete de Setembro, com 226, 148 e 115, respectivamente. Contudo, para o período seco-úmido, com o segundo maior índice de focos de calor, destacou-se as TI Pacaás Novos, Rio Guaporé e Uru-Eu-Wau-Wau, com 127, 64 e 53 focos, sendo que na TI Sete de Setembro, este efeito é ainda mais acentuado devido à fronteira com o Mato Grosso.

Os focos de calor em TI correspondem a apenas $2 \%$ das ocorrências no Estado de Rondônia, sendo que três delas representam 58\% desse total, são elas: TI Massaco, TI Karipuna e TI Uru-Eu-Wau-Wau (FILHO; TELES; NETO, 2009). Santos e Gomide (2015) destacaram que o município de Porto Velho possui um dos maiores rebanhos bovinos do país, o que afeta de forma direta as TI do estado, como a Parque do Aripuanã, Karipuna e Karitiana, as quais estão localizadas próximas a este município, sendo que, a TI Uru-Eu-WauWau também sofre pressão, visto que esta localiza-se entre duas rodovias.

As densidades de focos de calor obtidas pelo estimador Kernel são demonstradas na Figura 3, através das nuances de cores. No mesmo, é possível observar os locais com maiores densidades de focos nos quatro períodos, auxiliando na localização dos pontos mais sensíveis a possíveis incêndios.
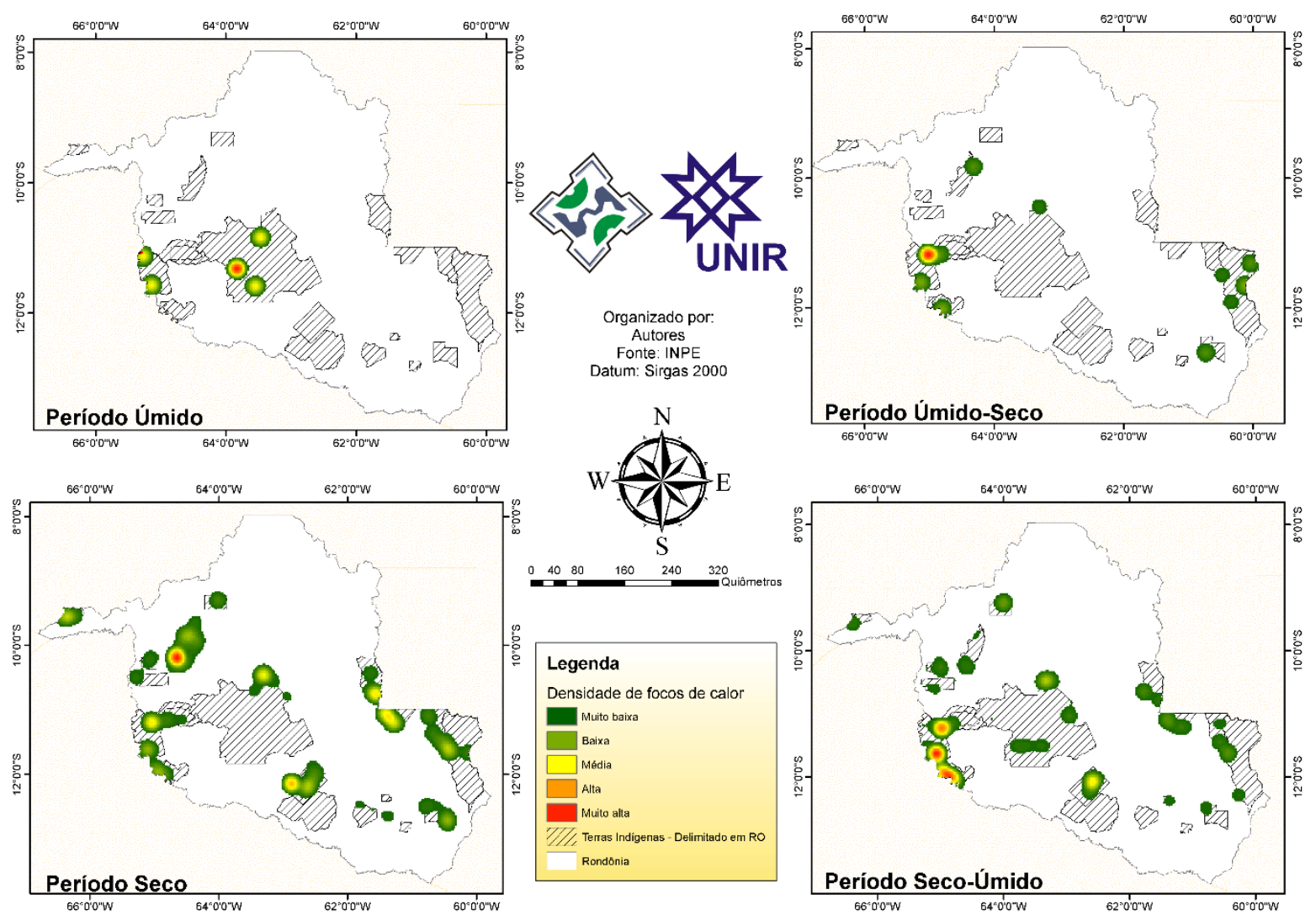

Figura 3 - Mapa de Kernel das ocorrências de focos de calor em Rondônia nos períodos Úmido, Úmido-Seco, Seco e Seco-Úmido do ano de 2015. 

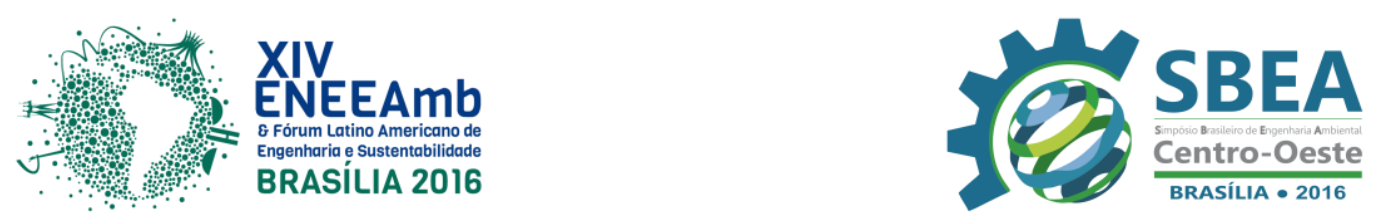

Pode-se ainda observar na Figura 3, uma concentração da densidade de focos de calor na extremidade oeste do estado, destacando as TI Sagarana, Rio Guaporé e Pacaás Novos, evidenciando o efeito de borda, comum em áreas de conflito e de difícil fiscalização e controle.

Os resultados mostram ainda os altos índices de focos de calor que ocorreram sobretudo nos limites das TI, supondo que a causa dos mesmos sejam falhas ou ausência de fiscalização em tais áreas, o que aumenta de forma significativa os casos de incêndios, contrariando o Decreto $\mathrm{n}^{\mathbf{0}}$ 7.747, de 2012, que institui a Política Nacional de Gestão Territorial e Ambiental de Terras Indígenas, o qual assegura à presença de TI como um importante mecanismo de proteção ambiental, e neste âmbito traz como principais objetivos, a proteção, fiscalização, vigilância e monitoramento ambiental das terras indígenas e seus limites.

\section{CONSIDERAÇÕES FINAIS}

Com bases nas análises realizadas, as TI do estado de Rondônia com maiores ocorrências de focos de calor estão localizadas próximas as rodovias, e/ou municípios que possuem a pecuária como principal atividade econômica. Considera-se que para essas áreas, os índices mais elevados de focos de calor foram identificados nos períodos secos, contrapondo-se ao ano analisado, no qual identificou-se um grande número de focos de calor também no período úmido-seco, o que pode estar relacionado ao fenômeno do El Niño ou ainda, às pressões antrópicas. Além disto, as falhas ou mesmo a insuficiência da fiscalização no estado, também podem ter relação direta com os altos índices de focos de calor encontrados nos limites de algumas TI.

\section{REFERÊNCIAS}

ABREU, F.A., SOUZA, J.S.A. Dinâmica Espaço-temporal de Focos de Calor em Duas Terras Indígenas do Estado de Mato Grosso: uma Abordagem Geoespacial sobre a Dinâmica do Uso do Fogo por Xavantes e Bororos. Floresta e Ambiente. ISSN 2179-8087 (online), 2015.

BRASIL. Decreto-lei n. 7.747, de 5 de junho de 2012. Institui a Política Nacional de Gestão Territorial e Ambiental de Terras Indígenas - PNGATI, e dá outras providências. Disponível em: <http://www.planalto.gov.br/ccivil_03/_ato2011-2014/2012/decreto/d7747.htm>. Acesso em: 28 de abril de 2016.

BRASIL. Decreto-lei n. 12.651, de 25 de maio de 2012. Dispõe sobre a proteção da vegetação nativa; altera as Leis $\mathrm{n}^{\mathrm{os}}$ 6.938, de 31 de agosto de 1981, 9.393, de 19 de dezembro de 1996, e 11.428, de 22 de dezembro de 2006; revoga as Leis $\mathrm{n}^{\text {os }} 4.771$, de 15 de setembro de 1965, e 7.754, de 14 de abril de 1989, e a Medida Provisória no 2.166-67, de 24 de agosto de 2001; e dá outras providências. Disponível em: <http://www.planalto.gov.br/ccivil_03/_ato20112014/2012/lei/112651.htm>. Acesso em: 07 de maio de 2016. 

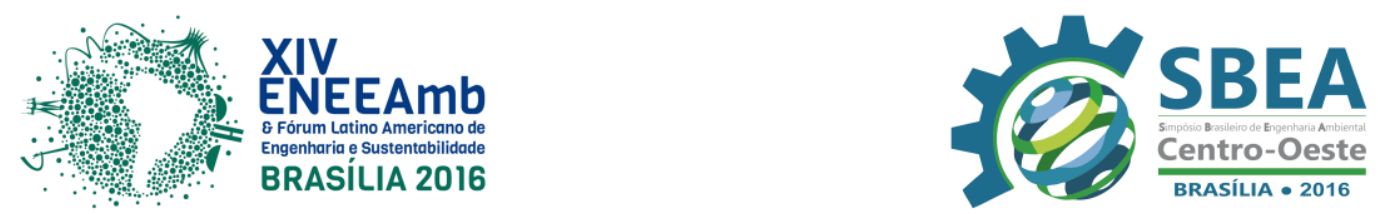

EDUARDO, O. L.; ARAGÃO, C.; SHIMABUKURO, Y. E.; LIMA, A.; ANDERSON, L. O.; BARBIER, N.; SAATCHI, S. Utilização de produtos derivados de sensores orbitais para o estudo de queimadas na Amazônia. In: Anais XVI Simpósio Brasileiro de Sensoriamento Remoto. Natal, RN. 2009. p. 919-925.

FILHO, E. B. S.; TELES, L. J. S.; NETO, L. A. S. Ocorrências de focos de calor no estado de Rondônia em 2007. Sociedade \& Natureza, v. 21, p. 123-140, 2009.

FUNAI. Fundação Nacional do Índio. O Brasil indígena. Disponível em: <http://www.funai.gov.br/index.php/indios-no-brasil/o-brasil-indigena-ibge>. Acesso em 18 Jun. 2013.

GONTIJO, G. A. B; PEREIRA, A. A.; Oliveira, E. D. S; JUNIOR, F. W. A.; Detecção de queimadas e validação de focos de calor utilizando produtos de Sensoriamento Remoto. XV Simpósio Brasileiro de Sensoriamento Remoto - SBSR. Curitiba - PR. Anais, p.7966, 2011.

IBGE - Instituto Brasileiro de Geografia e Estatística. Características gerais dos indígenas, 2010.

Disponível em:<http://www.ibge.gov.br/estadosat/temas.php?sigla=ro\&tema=censodemog2010_indig_un ive>. Acesso em:19 de abril de 2016.

INPE - Instituto Nacional de Pesquisas Espaciais. Queimadas e Incendios Florestais Monitoramento Orbital e Risco de Fogo. 2016. Disponível em: <http://www.inpe.br/queimadas>. Acesso em: 15 de abril de 2016.

Sustentabilidade ambiental no Brasil: biodiversidade, economia e bem-estar humano. Instituto de Pesquisa Econômica Aplicada. - Brasília: IPEA, 2010.

SANTOS, A. M. D.; GOMIDE, M. L. C. A ocupação no entorno das terras Indígenas em Rondônia, Brasil. Boletim Goiano de Geografia (Online), v. 35, p. 417-436, 2015.

SOUZA, N. P.de; SILVA, E. M. G. C; TEIXEIRA, M. D; LEITE, L. R; REIS, A. A. dos ; SOUZA, L. N. de ; JUNIOR, F. W. A; RESENDE, T. A. Aplicação do estimador de densidade Kernel em Unidades de Conservação na bacia do Rio São Francisco para análise de focos de desmatamento e focos de calor. In: Anais XVI Simpósio Brasileiro de Sensoriamento Remoto - SBSR, Foz do Iguaçu, PR. 2013.

SECRETARIA DE ESTADO DE DESENVOLVIMENTO AMBIENTAL. Boletim Climatológico de Rondônia - Ano 2010. COGEO - SEDAM / Coordenadoria de Geociências - Secretaria de Estado do Desenvolvimento Ambiental - v12, 2010 - Porto Velho: COGEO. Disponível em: 〈http://www.sedam.ro.gov.br>. Acesso em: 07 de Junho de 2015.

VITEL, C.S.M.N; FEARNSIDE, P.M; GRAÇA, P.M.L.A. Análise da inibição do desmatamento pelas áreas protegidas na parte sudoeste do Arco de desmatamento. In: Anais XIV Simpósio Brasileiro de Sensoriamento Remoto - SBSR, Natal. PE. 2009. 

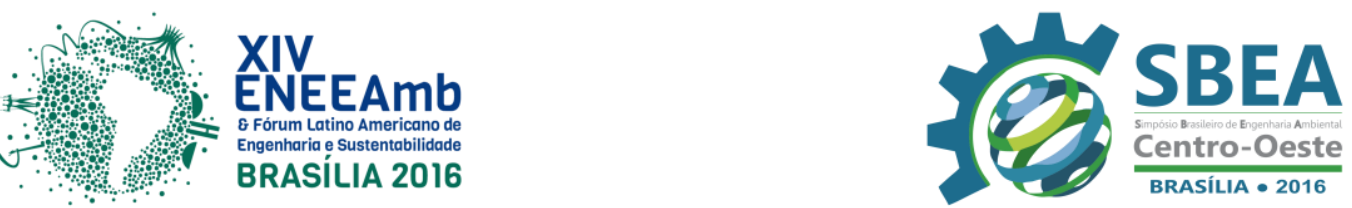

WEBLER, A. D.; GOMES, J. B.; AGUIAR, R. G.; ANDRADE, N. L. R.; AGUIAR, L. J. G. Mudanças no uso da terra e o particionamento de energia no sudoeste da Amazônia. Revista Brasileira de Engenharia Agrícola e Ambiental, v.17, p.868-876, 2013. 